\title{
Niche-based processes explaining the distributions of closely related subterranean spiders
}

\section{Pavlek, Martina}

2021-01

Pavlek, M \& Mammola , S 2021 , ' Niche-based processes explaining the distributions of closely related subterranean spiders ', Journal of Biogeography , vol. 48 , no. 1 , pp. 118-133 . https://doi.org/10.1111/jbi.13987

http://hdl.handle.net/10138/335707

https://doi.org/10.1111/jbi.13987

acceptedVersion

Downloaded from Helda, University of Helsinki institutional repository.

This is an electronic reprint of the original article.

This reprint may differ from the original in pagination and typographic detail.

Please cite the original version. 


\title{
Niche-based processes explaining the distributions of closely related subterranean spiders
}

\author{
Martina Pavlek ${ }^{1,2,3}$ (D) | Stefano Mammola ${ }^{4,5}$ (I)
}

${ }^{1}$ Ruđer Bošković Institute, Zagreb, Croatia

${ }^{2}$ Croatian Biospeleological Society, Zagreb, Croatia

${ }^{3}$ Department of Evolutionary Biology, Ecology and Environmental Sciences, Biodiversity Research Institute (IRBio), Universitat de Barcelona, Barcelona, Spain

${ }^{4}$ Laboratory for Integrative Biodiversity Research (LIBRe), Finnish Museum of Natural History (LUOMUS), University of Helsinki, Helsinki, Finland

${ }^{5}$ Molecular Ecology Group (MEG), Water Research Institute, National Research Council of Italy (CNR-IRSA), Verbania Pallanza, Italy

\section{Correspondence}

Martina Pavlek, Ruđer Bošković Institute, Bijenička 54, 10000 Zagreb, Croatia.

Email:martina.pavlek@gmail.com

Funding information H2020 Marie Skłodowska-Curie Actions, Grant/Award Number: 882221 and 749867; European Union's Human Resources Development Operational Programme, Grant/Award Number: HR.3.2.01-0015

Handling Editor: Rosemary Gillespie

\begin{abstract}
Aim: To disentangle the role of evolutionary history, competition and environmental filtering in driving the niche evolution of four closely related subterranean spiders, with the overarching goal of obtaining a mechanistic description of the factors that determine species' realized distribution in simplified ecological settings.

Location: Dinaric karst, Balkans, Europe.

Taxon: Dysderidae spiders (Stalita taenaria, S. pretneri, S. hadzii and Parastalita stygia). Methods: We resolved phylogenetic relationships among species and modelled each species' distribution using a set of climatic and habitat variables. We explored the climatic niche differentiation among species with $n$-dimensional hypervolumes and shifts in their trophic niche using morphological traits related to feeding specialization. Results: Climate was the primary abiotic factor explaining our species' distributions, while karstic and soil features were less important. Generally, there was a high niche overlap among species, reflecting their phylogenetic relatedness, but on a finer scale, niche shifts explained the realized distribution patterns. Trophic interaction was another important factor influencing species distributions - the non-overlapping distributions of three morphologically indistinguishable Stalita species is seemingly the outcome of competitive exclusion dynamics. The distribution of the fourth species, Parastalita stygia, overlaps with that of the other species, with several instances of coexistence within caves. As inferred from the morphology of the mouthparts, the mechanism that minimizes interspecific competition is the shift in the trophic niche of $P$. stygia towards a more specialized diet.

Main conclusions: We showed that similarity in niches only partly correlated with the phylogenetic distance among species, and that overlaps in species distributions are possible only when a parallel shift in diet occurs. Our work emphasized how even simplified environments still maintain the potential for diversification via niche differentiation. Ultimately, we provide an ecological explanation for the diversification of life in an important hotspot of subterranean diversity.
\end{abstract}

\section{KEYWORDS}

cave-dwelling spider, Dysderidae, ecological niche, MaxEnt, $\mathrm{n}$-dimensional hypervolume, niche shift, phylogeny, species distribution modelling, subterranean biology, troglobiont 


\section{1 | INTRODUCTION}

The idea that species can thrive within a specific set of environmental conditions, loosely their ecological niche, is central to ecology and evolution. The study of species' niches provides a conceptual foundation for understanding historical and current distribution patterns, ultimately allowing us to predict with some confidence how species will respond to climate change and other environmental modifications (Chase \& Leibold, 2003). One of the most popular representations of the niche is the $n$-dimensional hypervolume (Hutchinson, 1957), whereby the geometry of the niche space is approximated as an abstract Euclidean space defined by $n$ independent axes that correspond to abiotic and biotic factors affecting the organismal performance (Blonder, 2018a; Blonder et al., 2014; Holt, 2009). The recent proliferation of a variety of statistical methods to estimate these multidimensional spaces (e.g. Mammola \& Cardoso, 2020) have fuelled a renewed interest in exploring theoretical aspects related to the niche theory, such as the study of the eco-evolutionary process that shapes the geometry of a niche in space and time (Blonder, 2018a; Holt, 2009), but also more applied topics (e.g. Hanson et al., 2020). In spite of these advances, it remains notoriously challenging to tease apart the potential role of abiotic constraints and interspecific interactions in driving morphological and ecological niche shifts.

To approach niche-based studies, ecologists have typically used species within a given clade to explore if their niches are evolving, and if so, how fast and for what reasons (Holt, 2009; Liu et al., 2020). Typical models in this sense are radiations of surface-dwelling species (Gillespie et al., 2020), such as Darwin finches (Grant \& Grant, 2008), Anolis lizards (Gavrilets \& Losos, 2009) and cichlid fish (McGee et al., 2020). Yet, in most surface settings, the wide variability of the abiotic conditions and the great diversity of organisms and interactions represent important confounding factors that may limit our ability to disentangle niche-based processes. In contrast, the subterranean ecosystem is simpler, providing an ideal setting for eco-evolutionary studies (Mammola, 2019a; Mammola, et al., 2020; Sánchez-Fernández et al., 2018). Subterranean habitats are among the most widespread terrestrial ecosystems on Earth (Culver \& Pipan, 2019; Ficetola et al., 2019; Mammola, et al., 2019) which, unlike most surface systems, may persist relatively unchanged for millions of years (Gibert \& Deharveng, 2002). The absence of light and scarcity of nutrients limit the diversity and abundance of resident species, and the largely constant climatic conditions often translate into a narrow ecological niche for species that have adapted to life in caves (Culver \& Pipan, 2019). A similar simplified setting should permit to characterize the abiotic and biotic axes that define the niche of subterranean species with more confidence, and to approximate species interactions simply as the overlap in the resulting niche geometries.

We chose a group of closely related spiders in the family Dysderidae, which occur in caves across the northern part of the Dinaric karst, to explore mechanisms underlying niche evolution. Previous work on niche evolution among specific lineages of spiders has concluded that niche shifts, potentially resulting from interspecific competition, can permit co-occurrence in some areas (Kennedy et al., 2019), while in other areas, niche shifts were associated with abiotic variables, without co-occurrence (De Busschere et al., 2010). Among cave species, the role of abiotic constraints in shaping the geometry of the niche has often been emphasized (Mammola \& Isaia, 2017a). Conversely, biotic interactions have long been considered of secondary importance in the evolution of cave life (e.g. Poulson \& White, 1969), until different authors recently reassessed the role of competition as a potentially important selective force in subterranean species (e.g. Culver \& Pipan, 2015; Fišer et al., 2012; Mammola, 2019a; Trontelj et al., 2012). Recent studies discussed how interspecific interactions may be involved in driving morphological differentiation in coexisting cave spiders (e.g. in Dysdera in the Canary island; Arnedo et al., 2007 and Troglohyphantes in the Alps; Mammola, et al., 2018; Mammola, et al., 2020). Other studies suggested the potential role for interspecific interactions in determining segregation of species along environmental gradients in caves (e.g. Mammola et al., 2016; Resende \& Bichuette, 2016), as well as shift in diet, activity patterns (e.g. Novak et al., 2010) and climatic preferences (Mammola \& Isaia, 2017b).

Here, we set out to examine the interplay between these processes by first mapping current distribution ranges of our model species and exploring their phylogenetic relationships. We then reconstructed the shape of their ecological niche using $n$-dimensional hypervolumes (Blonder et al., 2014), and disentangled the ecological processes underlying niche differentiation (Mammola \& Cardoso, 2020). We finally interpreted niche overlaps in the light of shifts in dietary requirements, as inferred using morphological traits. We tested the following predictions:

1. the closer two species are from a phylogenetic standpoint, the more similar their niche space should be - a phenomenon termed 'niche conservatism' (Peterson, 1999; Wiens \& Graham, 2005);

2. insofar as competition requires spatial proximity, the higher degree of niche overlap should be attained in species with disjunct distributions;

3. species whose distributions overlap should show divergent morphologies (e.g. cheliceral and fang morphology; Arnedo et al., 2007; Rezač et al., 2008) that could serve to minimize direct competition and facilitate coexistence.

By linking niche differentiation to morphological and phylogenetic similarities among species, our overarching goal was to obtain a mechanistic description of the factors that determine each species' realized distribution.

\section{2 | MATERIALS AND METHODS}

\subsection{Model species and study area}

Dysderidae Koch, 1837 (Arachnida: Araneae), is a Western Palearctic family of spiders, whose representatives are frequently found in 
caves around the Mediterranean basin (Mammola et al., 2018). They do not build webs, but instead actively hunt their prey. Here, we focused on four species belonging to genera Stalita Schiödte, 1847 (Figure 1a) and Parastalita Absolon \& Kratochvíl, 1932 (Figure 1b), both belonging to the Rhodinae subfamily. These species are restricted to the northern half of the Dinarides and are highly specialized for subterranean life (Kratochvíl, 1970). Genus Stalita has four nominal species: S. taenaria Schiödte, 1847, S. hadzii Kratochvíl, 1934, S. pretneri Deeleman-Reinhold, 1971, and S. inermifemur Roewer, 1931. Considering the limited number of records (two caves only), we excluded S. inermifemur from the analysis. Parastalita is a monotypic genus with one species, $P$. stygia (Joseph, 1882), found to co-occur in several caves with S. taenaria and S. pretneri. Parastalita is easily differentiated from Stalita species by its elongated and horizontal chelicerae (which, in Stalita, are perpendicular to the ground), while morphologically, the three Stalita species are virtually identical and can be differentiated only by inspecting copulatory organs (Deeleman-Reinhold, 1971; Kratochvíl, 1970).

The Dinarides (Dinaric Alps) is a mountain range in the western Balkans, whose carbonate part, the Dinaric karst, harbours more than 20,000 caves (Zupan Hajna, 2019) and is a global hotspot of subterranean biodiversity with more than 900 obligate subterranean species (Culver et al., 2006; Sket, 2012; Sket et al., 2004). With 101 species, spiders are the second-most numerous terrestrial group in Dinaric caves after beetles (Pavlek \& Ribera, 2017; Platania et al., 2020; Sket et al., 2004; Wang \& Li, 2010).

\section{2 | Molecular procedures and phylogenetic analyses}

In order to explore phylogenetic relationships among the four studied spiders, we selected representatives of each of them, as well as of the other three Rhodine genera so as to capture the whole subfamily diversity. For Mesostalita, we included two of three known species, for Rhode two of eight, and for Stalitella we included the only known species. Furthermore, we selected a representative for each of the other two Dysderidae subfamilies, Harpacteinae and Dysderinae. The list of the samples used and their GenBank ${ }^{\circledR}$ accession codes are available in Appendix S1.

The laboratory procedures of genomic DNA extraction and PCR amplifications follow Platania et al. (2020). We amplified fragments of five genes: the mitochondrial genes encoding cytochrome $c$ oxidase subunit I (COI) and ribosomal RNA 16S, and the nuclear genes for histone $\mathrm{H} 3$ and ribosomal RNA $28 \mathrm{~S}$ and 18S. The information on the primers used, amplification protocol as well as the profiles for the PCR amplifications are available in Appendix S1. We sent unpurified PCR products to the Macrogen services for sequencing. We assembled, reviewed and edited sequence chromatograms of each sample with Geneious v. 8.1.9 (Kearse et al., 2012). We automatically aligned all genes using default options in the Geneious plugin of the alignment program MAFFT v. 7.017 (Katoh et al., 2002), and concatenated them in a
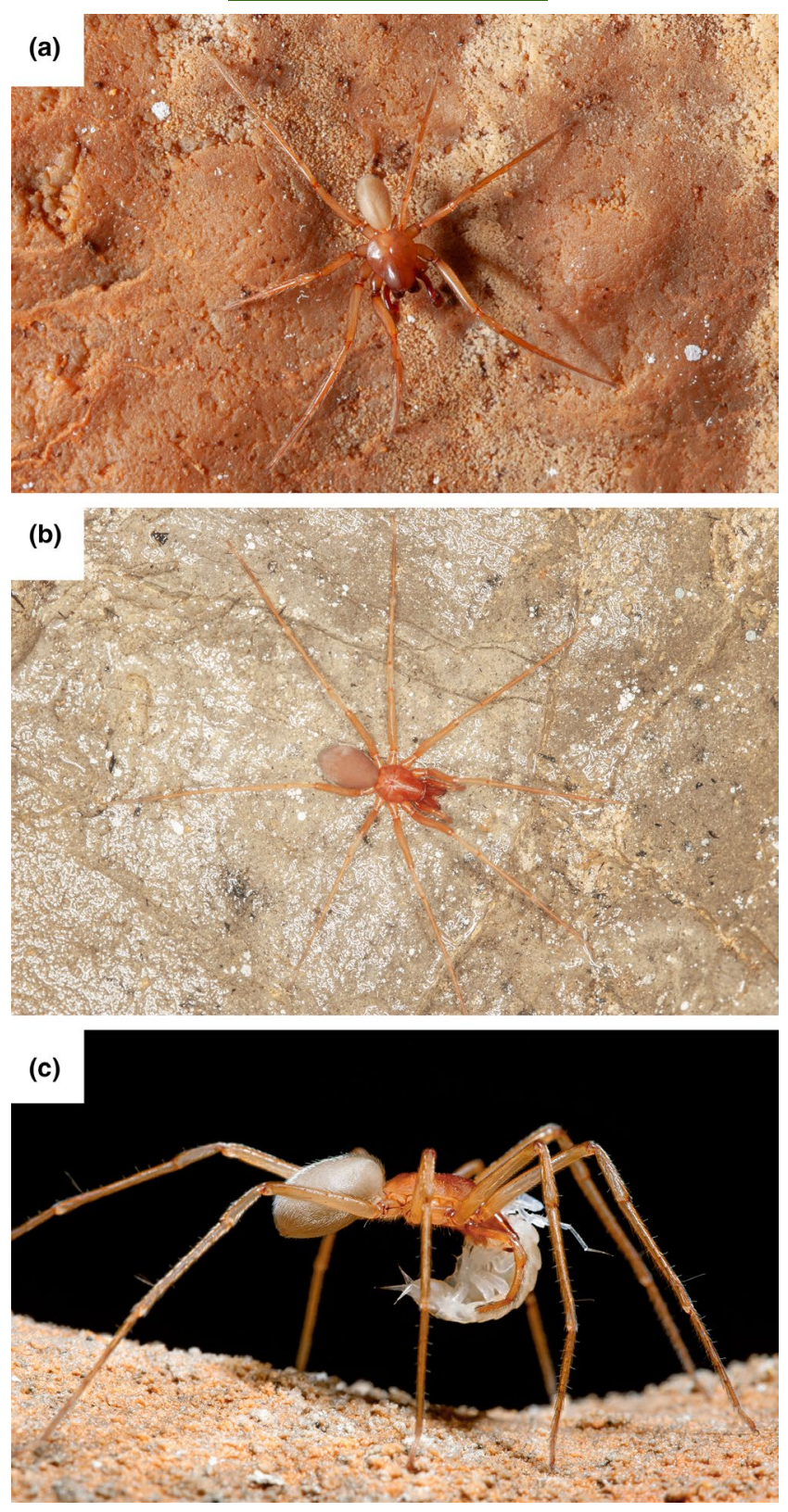

FIGURE 1 (a) Stalita taenaria Schiödte, 1847; photo credit Helena Bilandžija, (b) Parastalita stygia (Joseph, 1882); photo credit Jana Bedek, (c) P. stygia feeding on a woodlouse Alpioniscus iapodicus Bedek, Horvatović \& Karaman, 2017; photo credit Kazimir Miculinić

super matrix with 19 terminals: $676 \mathrm{bp}$ of the COI, $976 \mathrm{bp}$ of the $16 \mathrm{~S}, 810 \mathrm{bp}$ of the $18 \mathrm{~S}, 853 \mathrm{bp}$ of the $28 \mathrm{~S}$ and $328 \mathrm{bp}$ of the H3. We inferred the best maximum likelihood tree with IQ-TREE v. 2.0 (Minh et al., 2019) . First, we used ModelFinder to select the best-fit partitioning scheme and corresponding evolutionary models (Kalyaanamoorthy et al., 2017), and then we inferred the best tree topology and estimated clade support by means of 1,000 replicates of non-parametric bootstrapping. We used MrBayes v3.2.6 (Ronquist \& Huelsenbeck, 2003) to implement Bayesian inference. We assessed the best partitioning scheme and corresponding evolutionary model with Partition Finder v2.1.1 (Lanfear et al., 2017). 
The analysis was run for 30 million generations, sampling each 1,000 , with eight simultaneous Markov Chain Monte Carlo chains, 'heating temperature' of 0.15 and an initial burn-in of $10 \%$. We expressed support values as posterior probabilities. We monitored the convergence of the chains, the number of burn-in generations and correct mixing with Tracer v. 1.7 (Rambaut et al., 2018).

\section{3 | Species distribution modelling}

We conducted all ecological analyses in R (R Core Team, 2018). We used species distribution modelling (SDM) to map the distribution of our model species in the Dinaric karst and to identify key environmental predictors driving the observed distribution patterns. Although we acknowledge that SDM is a correlative way to estimate species range, having large uncertainties and often over- or underfitting the real distribution, it still proved useful for answering a wide range of ecological questions ( $>6,000$ studies up to now; Araújo et al., 2019).

\subsection{1 | Occurrence data}

We assembled a dataset with georeferenced records for the four species (Figure 2) based on material deposited in the collection of the Croatian Biospeleological Society, the collections of the Universities of Ljubljana and Barcelona, the private collection of Roman Ozimec and on an extensive survey of literature (see https:// doi.org/10.6084/m9.figshare.12613193). Occurrences datasets for cave-dwelling species are often unevenly distributed in space due to the fact that most speleological research is concentrated in more easily accessible caves and karst areas (Mammola \& Leroy, 2018). To avoid local overexpression of the numbers of occurrences as a result of sampling heterogeneity, we performed a spatial correction of occurrence points of each species. We tested different spatial corrections: (a) a sampling bias grid at the resolution of the environmental predictors, or (b) a sampling bias grid and subsequent spatial thinning of occurrence points based on minimum distances of $0.01,0.02$ and 0.05 relative to the species range, as implemented in the 'red' package (Cardoso, 2017). Given that models fitted with occurrences

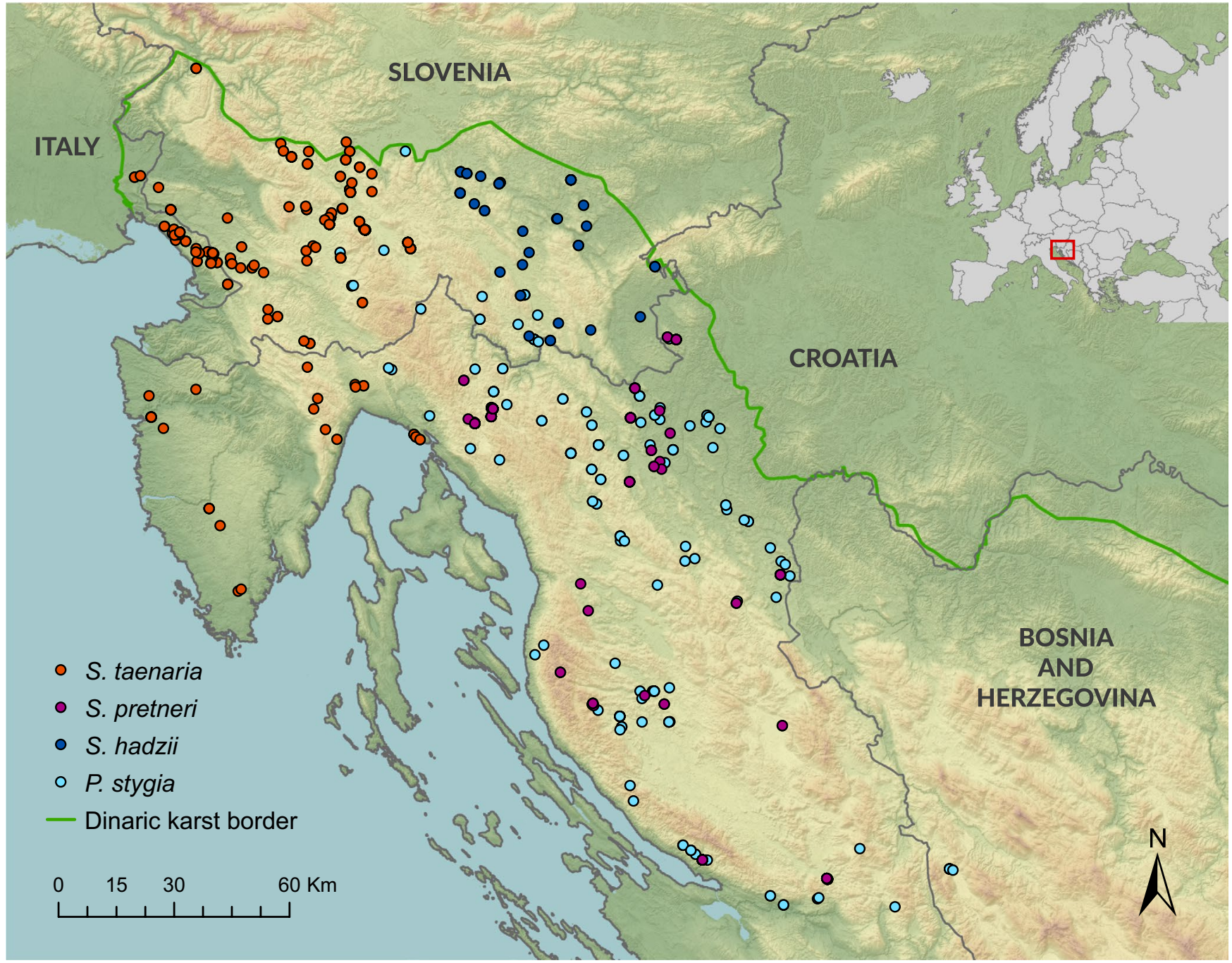

FIGURE 2 A map with occurrence records of Stalita taenaria, S. pretneri, S. hadzii and Parastalita stygia 
corrected using the first approach performed better for all species (as measured with Boyce index; see later), we kept this spatial correction protocol in all analyses.

\subsection{2 | Environmental predictors}

To depict subterranean conditions across north Dinarides, we selected a combination of topographical, bioclimatic, geological and soil variables (Table 1), all at a resolution of $30 \mathrm{arc}-\mathrm{sec}$. A shape file of the hydrogeological map of Dinaric karts was obtained from the Diktas project website (http://diktas.iwlearn.org/), providing layers that represent aquifers with different levels of permeability. Specifically, two Karst-fissure layers, one with good and the other with moderate permeability, two Intergranular layers with good and moderate permeability (we combined those into categorical variable 'Intergranular'), and lastly, one layer with poor permeability and another with impermeable rocks which we combined into the category 'Impermeable'. We rasterized all these shapefiles and used them as categorical binary predictors. We downloaded bioclimatic variables and elevation data from the WorldClim website (Fick \& Hijmans, 2017), and extracted rasters of soil properties from SoilGrids database (Hengl et al., 2017).

We tested multicollinearity (Braunisch et al., 2013) among continuous predictors using Pearson $r$ correlation, setting a threshold for culling collinear variables at $|r|>0.7$. We inspected relationships between continuous and categorical variables graphically using boxplots (Zuur et al., 2010).

\subsection{3 | Accessible area}

We calibrated each SDM within the accessible area, namely, the geographic extent that a certain species was supposedly capable of occupying throughout its evolutionary history (Barve et al., 2011). Because we had no quantitative knowledge on the actual dispersal potential of our model species within the Dinaric karst, we used half the distance between the two distant-most occurrences of each

TABLE 1 Variables selected in the species distribution models and their relevance to represent subterranean conditions (rationale for inclusion). Non-collinear variables introduced in the model are highlighted in bold

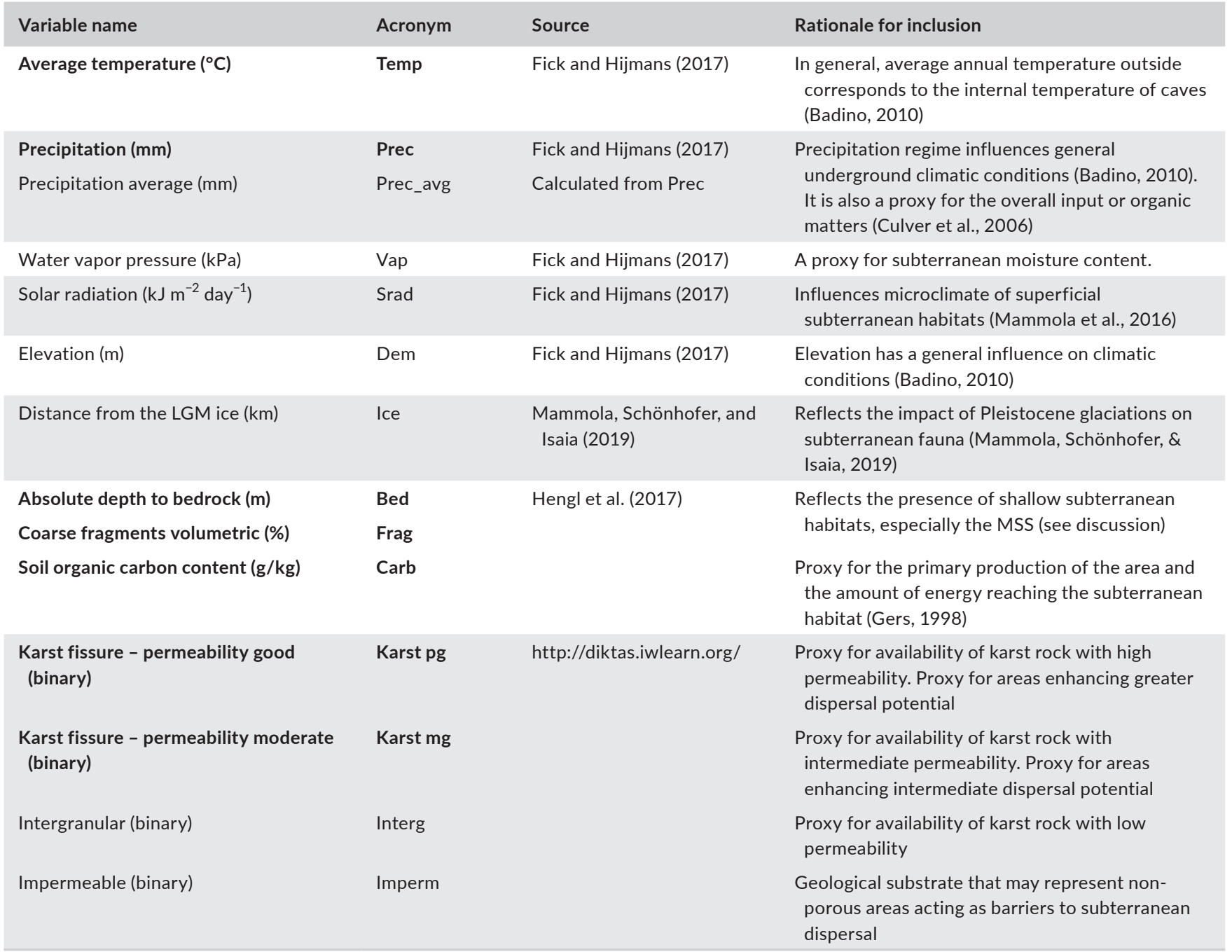


species to approximate it. We buffered each species occurrences by a radius equivalent to this distance, and combined all circles in a final shapefile that we used to crop the environmental predictors. We also faced an issue related to data limitation because the shape file of the hydrogeological map does not extend beyond Dinaric karst in the north-western part. That is why we were forced to artificially cut the accessible area at 46.2 North and 21.0 West. However, we believe this is a reasonable assumption given that our model species are not found on non-soluble rock, meaning that areas outside the Dinaric karst should be unsuitable for species dispersal anyway.

\subsection{4 | Modelling procedure}

As we lacked reliable absence data for our model species, we constructed SDMs using a presence-only algorithm (MaxEnt), with the function maxent in the 'dismo' R package (Hijmans et al., 2014). Considering that we had $<100$ independent records for most of the species, we specified MaxEnt's feature classes and regularization multiplier parameters manually (Morales et al., 2017), by estimating their best configuration with the ENMevaluate function in the 'ENMeval' R package (Muscarella et al., 2014).

To validate models, we ran 50 bootstrap replicates of each model, keeping a random partition of $20 \%$ of the points from each run to assess predictive performance. We expressed predictive ability as the Boyce index (Boyce et al., 2002), which we calculated with the ecospat.boyce function in the 'ecospat' R package (Broennimann et al., 2018). This is an appropriate metric for presence-only models (Hirzel et al., 2006). Once each model had been validated, we generated a final model using the entire set of occurrence points and projected it within the accessible area. We estimated the relative contribution of each variable to the construction of the final models via permutation importance.

\subsection{Niche partitioning}

We represented the species' ecological niche spaces as $n$-dimensional hypervolumes (Hutchinson, 1957), which we constructed with the 'hypervolume' R package (Blonder, 2018b). We generated hypervolumes using the non-collinear continuous variables introduced in the SDMs. We rescaled each variable by subtracting mean and dividing by standard deviation (pooling the data for all species), to achieve the same dimensionality for all hypervolumes axes (Blonder et al., 2014, 2018). We delineated hypervolume with a Gaussian kernel density estimator (Blonder et al., 2018), and estimated the optimal bandwidth for each axis through cross-validation (Duong \& Hazelton, 2005).

We characterized each niche by calculating total hypervolume's volume, dispersion and evenness (Mammola \& Cardoso, 2020) using the 'BAT' R package (Cardoso et al., 2015, 2020). We assessed pairwise niche differentiation among hypervolumes of the four species using both a measure of similarity ( $\beta$ diversity) and of distance (distance between centroids). While the measure of similarity is designed to explore the net overlap among hypervolumes, the distance between centroids provides empirical information about hypervolumes' spatial position relatively to one another, namely, how far they are in the multidimensional space (Mammola, 2019b). We estimated $\beta$-diversity through the kernel.beta function (Mammola \& Cardoso, 2020), decomposing overall differentiation $\left(\beta_{\text {total }}\right)$ into two components: the replacement of space between hypervolumes $\left(\beta_{\text {replacement }}\right)$, and net differences between the amount of space enclosed by each hypervolume ( $\left.\beta_{\text {richness}}\right)$. $\beta_{\text {replacement }}$ is meant to reflect niche shift processes and $\beta_{\text {richness }}$ variations in niche volume of one species with respect to the other (i.e. expansion or contraction) (Carvalho \& Cardoso, 2020). $\beta_{\text {total }}$ ranges continuously between 0 (identical niches) and 1 (fully dissimilar niches), and $\beta_{\text {total }}=\beta_{\text {replacement }}+\beta_{\text {richness. }}$.

\section{5 | Morphological traits related to trophic specialization}

We assessed morphological differentiation among species by using traits related to feeding specialization, which in Dysderidae are expressed as the ratios of basal cheliceral segment and cheliceral fang length to the carapace length (Rezač et al., 2008). Specifically, Rezač et al. (2008) divided the Dysdera chelicerae into five categories based on their morphology, demonstrating that species with elongated chelicerae [basal cheliceral segment length/carapace length (BS/C) $\geq 0.47$; fang length/carapace length $(F / C) \geq 0.45$ ] or with modified fang were specialists for feeding on woodlice, while the ones with unmodified cheliceral morphology $(B S / C \leq 0.34$ and $F / C \leq 0.41)$ were generalists.

We measured those ratios in ten adult individuals per each of the four studied species (five males and five females), except for $S$. hadzii for which only four adult males were available (Appendix S1). We tested for differences in the ratio among species and sexes with analysis of variance (ANOVA).

\section{RESULTS}

\section{1 | Phylogenetic relationships among species}

Results of the phylogenetic analyses are shown in Figure 3. Both methods recovered the same tree topology: all Rhodinae genera were confirmed as monophyletic, and three Stalita species were recovered as congeneric, $S$. hadzii and $S$. tenaria being more closely related, and sister to $S$. pretneri. Parastalita was recovered as sister to Stalitella, the genus occurring in the south of the Dinarides (Deeleman-Reinhold, 1971), and the two of them as sister to Stalita.

\subsection{Species distribution modelling}

As a result of collinearity analysis (Appendix S2), we selected the following variables for modelling each species' distribution: average 
FIGURE 3 Maximum likelihood tree inferred from a concatenated matrix of five markers. Numbers next to nodes correspond to maximum likelihood bootstrap values on the left, and Bayesian posterior probabilities on the right. Nodes without support values are supported with both methods: $>75$ bootstrap support and $>95$ Bayesian posterior probabilities. The tree was rooted with Segestria sp., a member of Segestridae, a sister family to Dysderidae

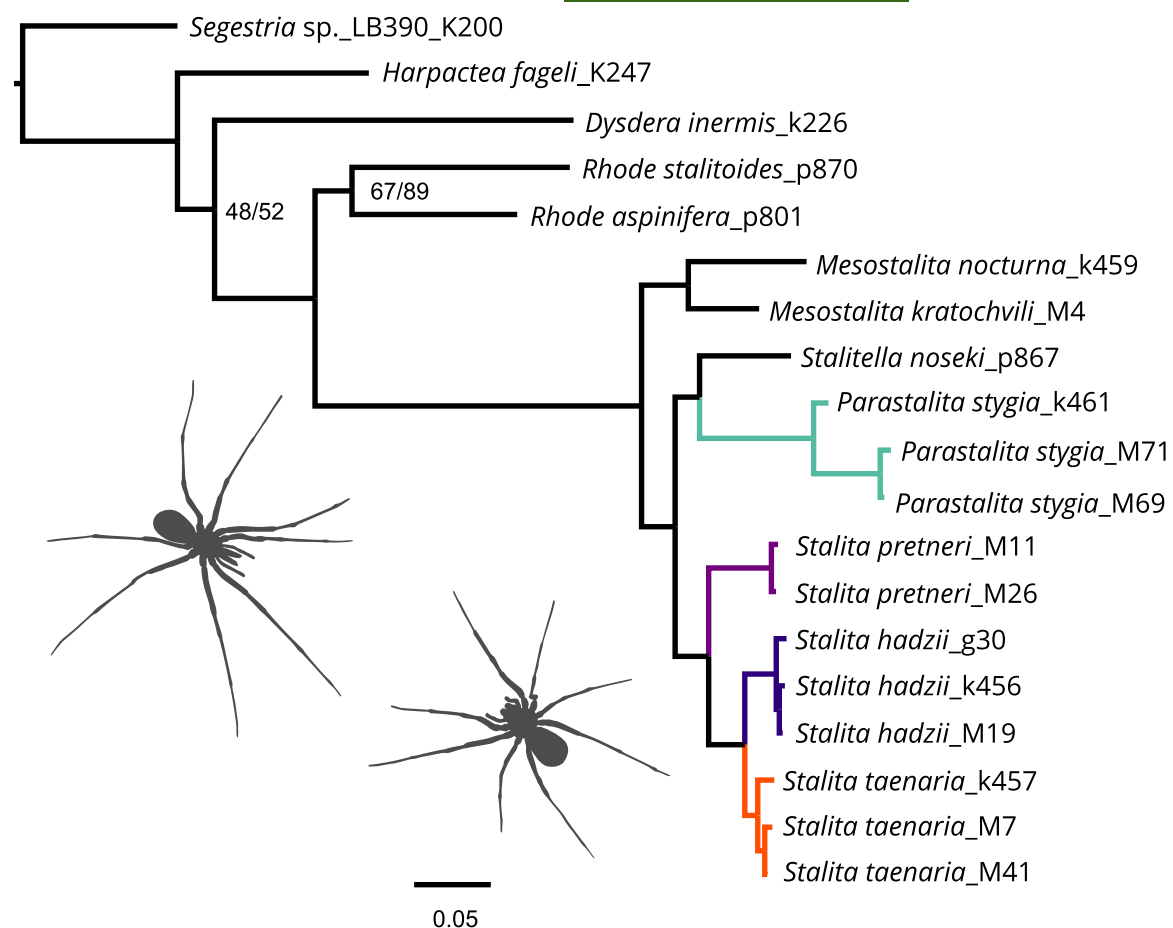

TAB LE 2 Statistics about the species distribution models and hypervolume analyses. Variables abbreviations are given in Table 1

\begin{tabular}{|c|c|c|c|c|c|c|c|c|c|c|c|c|}
\hline & \multirow[b]{2}{*}{ Number } & \multirow[b]{2}{*}{$\begin{array}{l}\text { Boyce } \\
(\text { mean } \pm S D)\end{array}$} & \multicolumn{7}{|c|}{ Permutation Importance } & \multicolumn{3}{|c|}{ Hypervolume } \\
\hline & & & Prec & Temp & Frag & Carb & Bed & $\begin{array}{l}\text { Karst } \\
\mathrm{mp}\end{array}$ & $\begin{array}{l}\text { Karst } \\
\text { pg }\end{array}$ & Volume & Dispersion & Evenness \\
\hline Parastalita stygia & $\begin{array}{l}129 \\
(118)\end{array}$ & $0.83 \pm 0.09$ & 71.3 & 10.6 & 11.0 & 1.7 & 1.9 & 2.8 & 0.7 & $1,727.5$ & 4.2 & 0.05 \\
\hline Stalita taenaria & $99(91)$ & $0.82 \pm 0.08$ & 46.0 & 27.0 & 4.2 & 1.7 & 0.5 & 0.0 & 20.0 & $2,415.1$ & 4.4 & 0.05 \\
\hline Stalita hadzii & $24(24)$ & $0.67 \pm 0.26$ & 28.5 & 10.4 & 26.3 & 0 & 2.2 & 0 & 32.6 & 93.4 & 2.7 & 0.04 \\
\hline
\end{tabular}

Note: Number $=$ Number of occurrence records (in parentheses, the number of records after correcting for spatial sampling heterogeneity). Boyce $=$ Boyce index (mean $\pm S D$ of 50 runs)

temperature, precipitation, absolute depth to bedrock, coarse fragments volumetric, soil organic carbon content and karst fissure-permeability good and moderate. The number of occurrences used to model the distribution of each species is given in Table 2. The estimated optimal MaxEnt configuration was linear feature class for all species and, additionally, quadratic feature classes for $P$. stygia and $S$. taenaria; the optimal regularization parameter was 0.5 for $P$. stygia and S. pretneri and 1.5 for S. hadzii and S. taenaria.

All models had a good explanatory ability (all Boyce indexes >0.6; average of 50 bootstraps; Table 2). The model for P. stygia predicted a slightly wider suitable area in the northern part of the species distribution, in regions where $S$. hadzii and $S$. taenaria occur (Figure 4a). Conversely, the model failed to predict suitable areas in the southernmost edge of $P$. stygia distribution. The model for $S$. pretneri predicted a core distribution area in the central part of the northern Dinaric karst, as well as some suitable areas north-west to the known localities, which overlap with the regions inhabited by
S. hadzii and S. taenaria (Figure 4b). The projected distribution for S. hadzii slightly overextended westward and southward, corresponding to karstic areas occupied by one of the other three species (Figure 4c). And finally, for S. taenaria, the model predicted a wider suitable area in the south and east directions, although with low probability (Figure 4d). Stalita hadzii and S. pretneri are found in the east and south-east areas, respectively, while in the south direction, in the area of north Adriatic islands, no cave-dwelling Dysderidae have been recorded so far. The model failed to predict suitable areas, or predicted low probability, in the south-west part of the species distribution. In general, for all species there are regions inside their current distributions with a high probability of suitable habitats, but with no records, indicating possible under-sampled areas.

Climatic variables were the most important predictors of species distributions. For $P$. stygia, precipitation alone explained more than $70 \%$ of the modelled distribution, and together with temperature more than $80 \%$ (Table 2). Similarly, for S. taenaria, 

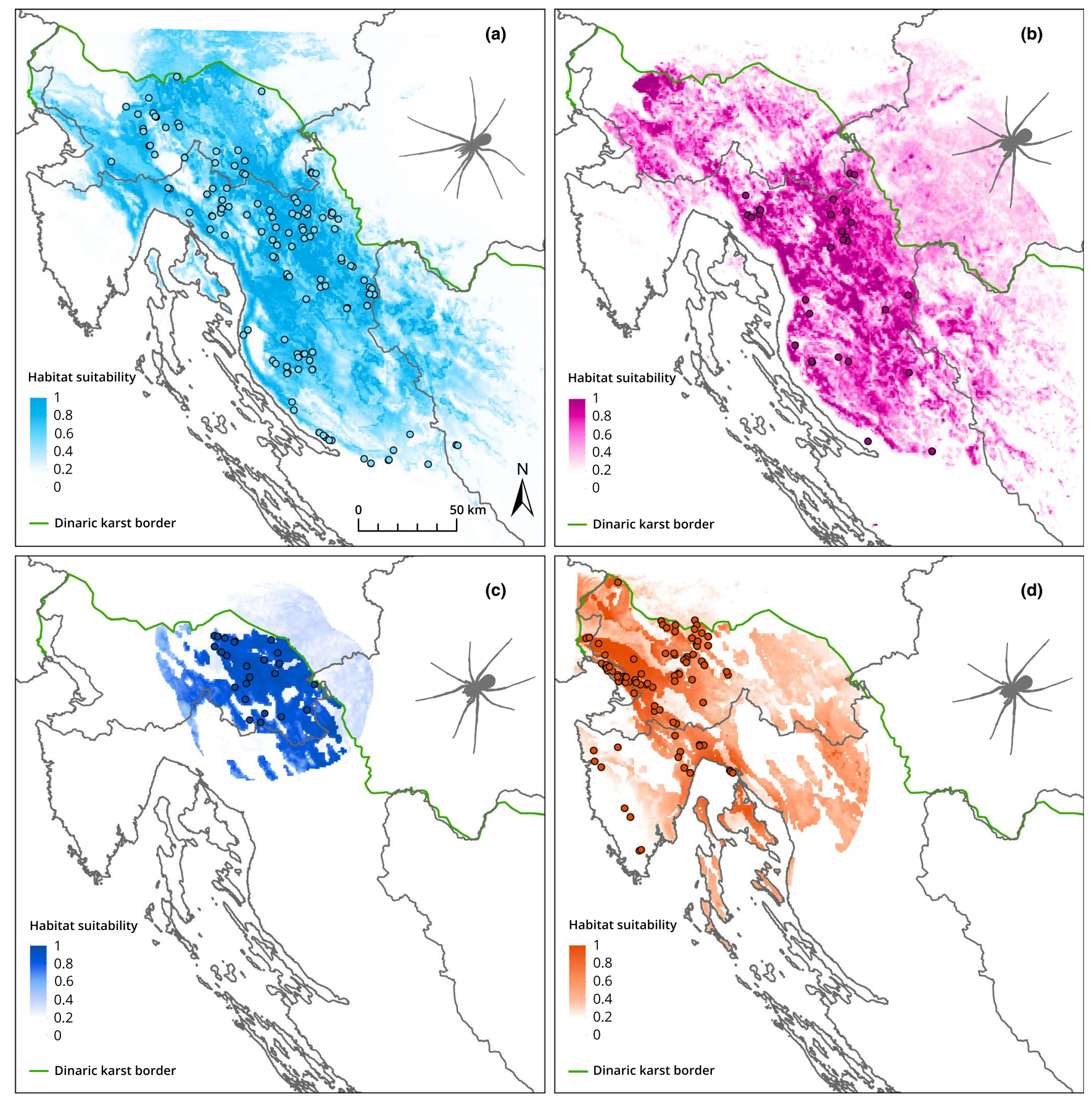

FIGURE 4 Potential distributions of the four studied species as projected by species distribution models. Circles represent occurrences. (a) Parastalita stygia, (b) Stalita pretneri, (c) S. hadzii and (d) S. taenaria

climatic variables explained $73 \%$ of the modelled distribution. The presence of highly permeable rocks was important for $S$. taenaria (20\%) and S. hadzii (33\%), whereas other karst layers turned out to be unimportant drivers of the distribution of all species. Fragmentation explained almost $30 \%$ of the modelled distribution for S. hadzii and S. pretneri, while the effect of other soil variables was negligible in all models. Stalita hadzii was the only species for which karst and soil features were more important than climatic variables, cumulatively explaining more than $60 \%$ of the modelled distribution.

\subsection{Niche overlap}

As emphasized by the generally short distance between niche centroids, species niches were close to each other in the multidimensional space (Figure 5). Pairwise $\beta$-diversity values pointed to the existence of both niche contraction and shift processes (Table 3). Stalita hadzii had the narrowest niche (volume of hypervolume two orders of magnitude less voluminous than that of the other species; Table 2), which was mostly nested within niches of the other three species, indicating niche contraction. This is 
also shown by the narrow range of actual environmental conditions experienced by S. hadzii (Figure 6). Stalita taenaria had the broadest and most dispersed niche (Table 2), quite dissimilar to all the other species ( $\beta_{\text {total }}$ values all above 0.6 ; Table 3 ). The high values of pairwise $\beta_{\text {replacement }}$ with respect to $P$. stygia and S. pretneri (Table 3) also indicate a niche shift in the direction of exploiting more humid and warmer regions, whereas differences with $S$. hadzii were only attributable to $\beta_{\text {richness }}$ (Figure 5). Also, S. taenaria in general tolerates a wider range of temperature and humidity (precipitation) conditions (Figure 6).

Parastalita stygia and S. pretneri had the most similar niches, which is not surprising considering that the distribution area of the two species overlaps to a great deal; in fact, they coexist in 18 caves. Niches of P. stygia and S. taenaria were only moderately similar (Table 3), reflecting their coexistence in only 9 caves and only in a part of $S$. taenaria distribution area. The greater niche dissimilarity between P. stygia and S. hadzii (Table 3) was also reflected in the fact that they were never found in the same cave, although $P$. stygia's distribution circumscribes $S$. hadzii ones.

\section{4 | Trophic segregation}

Measured morphological traits evidenced a significant differentiation between Parastalita and Stalita (Figure 7), supporting their trophic segregation. Following the work by Rezač et al. (2008), we can infer that Stalita species are generalists as they have unmodified chelicerae, while $P$. stygia, with its elongated chelicerae ('slightly elongated' category sensu; Rezač et al. (2008)) is a specialist.

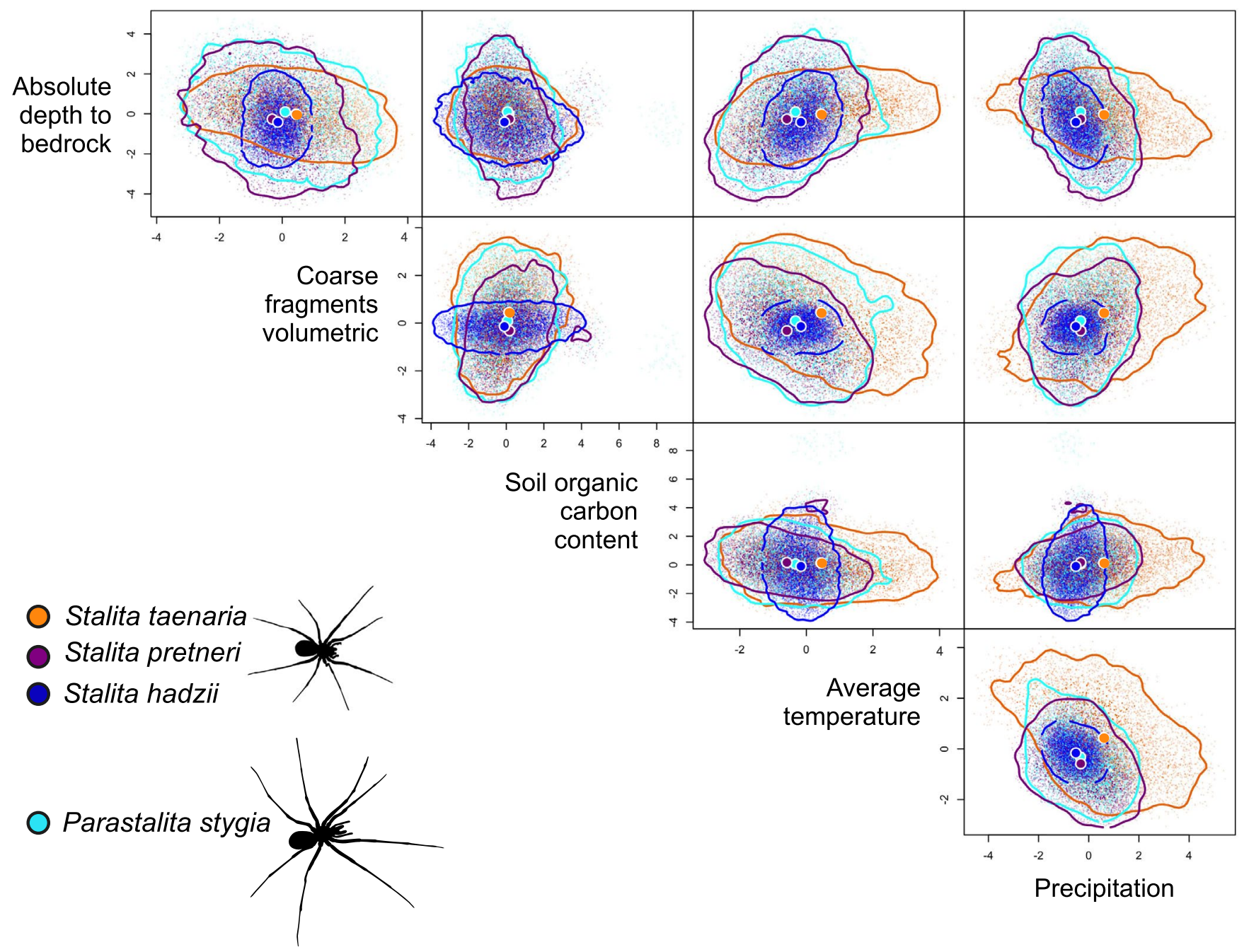

FIGURE 5 Pair plots showing the estimated five-dimensional hypervolumes for Parastalita stygia, Stalita hadzii, S. pretneri and S. taenaria. The cloud of coloured points for each species is composed of 5,000 points stochastically sampled from the inferred hypervolume, and represents the real hypervolume boundary. Contour lines are drawn for visual presentation. Variables are rescaled. Metrics relative to each hypervolume are in Table 2, whereas pairwise $\beta$-diversity and distance between centroid in Table 3 


\begin{tabular}{lllll} 
& Parastalita stygia & Stalita hadzii & Stalita pretneri & $\begin{array}{l}\text { Stalita } \\
\text { taenaria }\end{array}$ \\
\hline P. stygia & - & 0.61 & 0.59 & 1.25 \\
S. hadzii & $0.95=0.01+0.94$ & - & 0.59 & 1.45 \\
S. pretneri & $0.39=0.09+0.30$ & $0.93=0.02+0.91$ & - & 1.68 \\
S. taenaria & $0.65=0.42+0.23$ & $0.97=0.01+0.96$ & $0.76=0.34+0.42$ & - \\
\hline
\end{tabular}

TABLE 3 Pairwise niche differentiation among $n$-dimensional hypervolumes of the four species, as estimated through a measure of overlap (below the diagonal; $\beta_{\text {total }}=\beta_{\text {replacement }}+\beta_{\text {richness }}$ ) and of distance (above the diagonal; distance between centroids) (a)

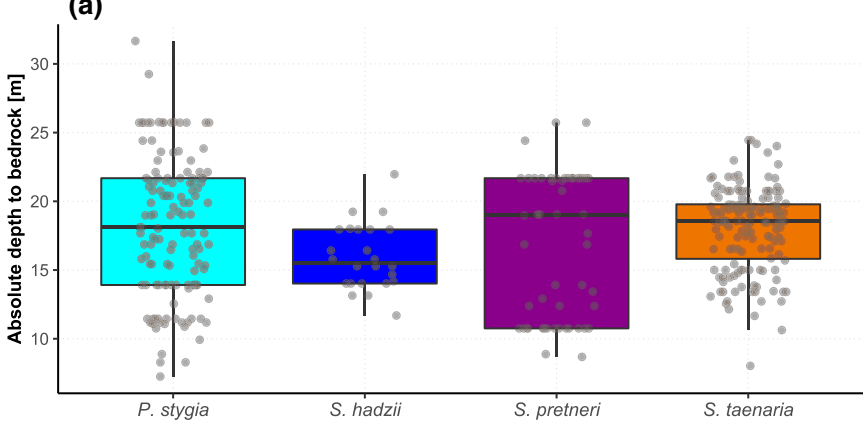

(c)

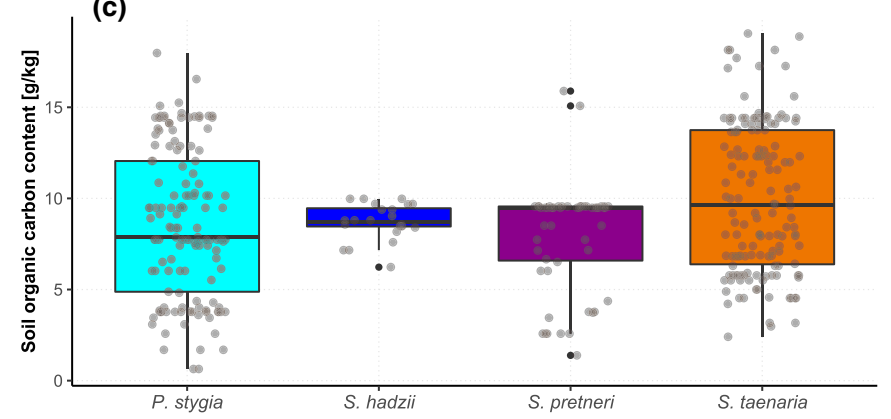

(e)

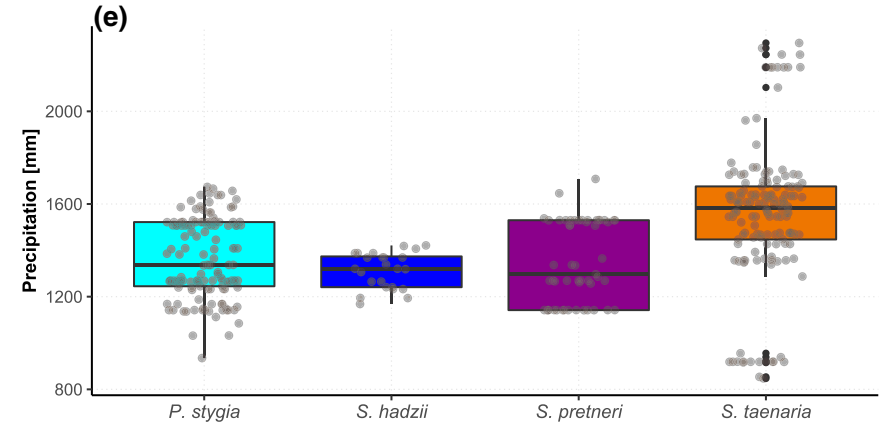

(b)

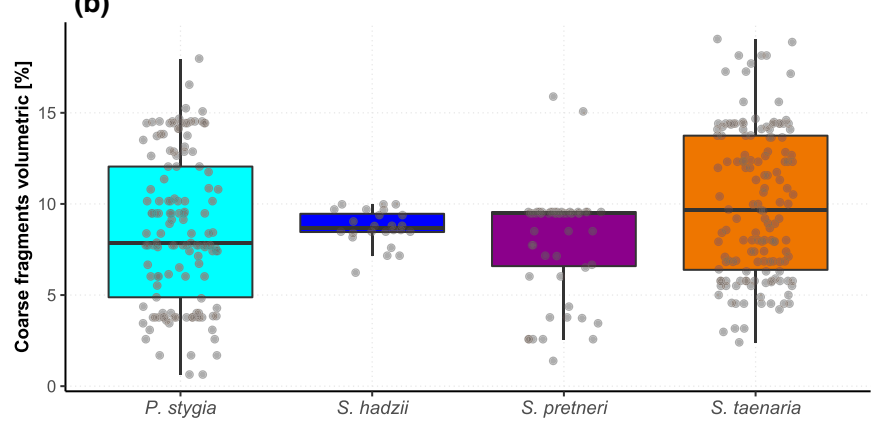

(d)
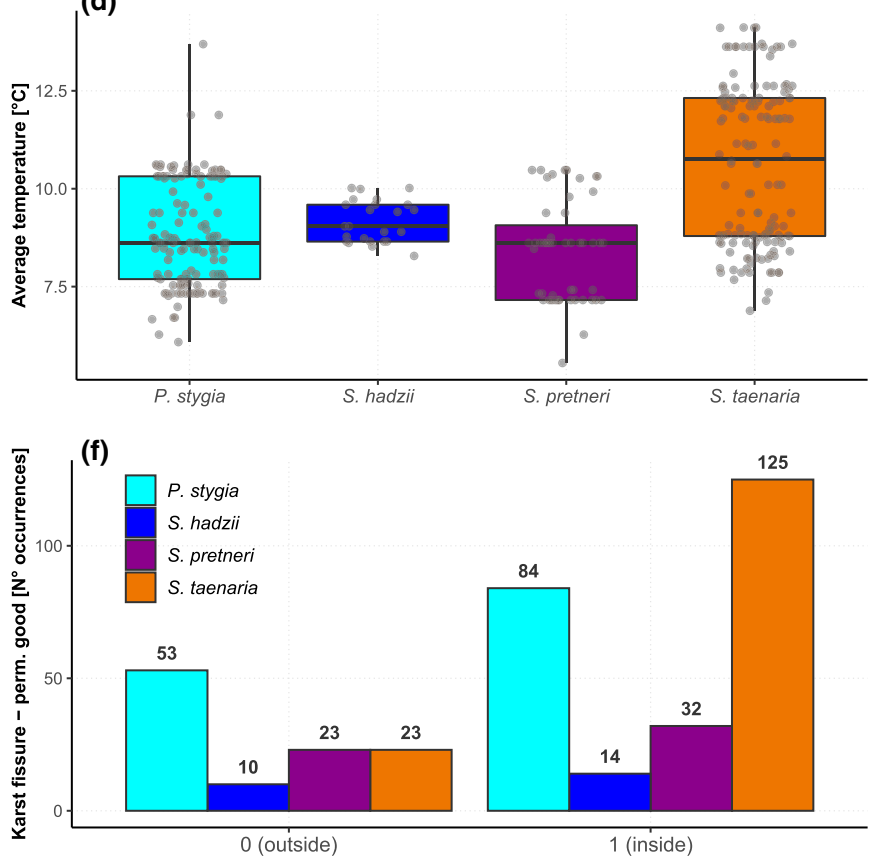

FIGURE 6 Environmental conditions experienced by the four species across their distribution range. Grey dots in a-e represent the real extracted values, whereas black dots represent outliers

\section{4 | DISCUSSION}

\subsection{Niche differentiation in closely related species}

We showed that multiple niche-based processes are responsible for the current distribution patterns of our model species at the restricted spatial scale of the northern Dinaric karst. Three congeneric species, S. taenaria, S. hadzii and S. pretneri, do not overlap in their distributions. Competition could be an important factor determining their distribution patterns, given that Stalita species are almost identical in all somatic characters (Deeleman-Reinhold, 1971; Kratochvíl, 1970) as well as in the cheliceral morphology (Figure 7). On the other hand, the distribution of the fourth species, P. stygia, largely overlays with that of $S$. pretneri, and to a smaller extent, with that of $S$. taenaria. In at least 27 of 255 caves included in the distribution database, $P$. stygia has been found coexisting with other Stalita species.

We found that niche differentiation is not strictly related to phylogenetic history: closely related species from a genetic standpoint (S. taenaria and S. hadzii) are not the most similar in terms of ecological niche. At the same time, S. pretneri has a more similar niche to the distantly related $P$. stygia than to its congenerics. This would suggest that the ecological specialization in this complex of species is evolving in response to recent adaptive pressures. This finding parallels the phenomena observed in crustacean inhabiting groundwaters 

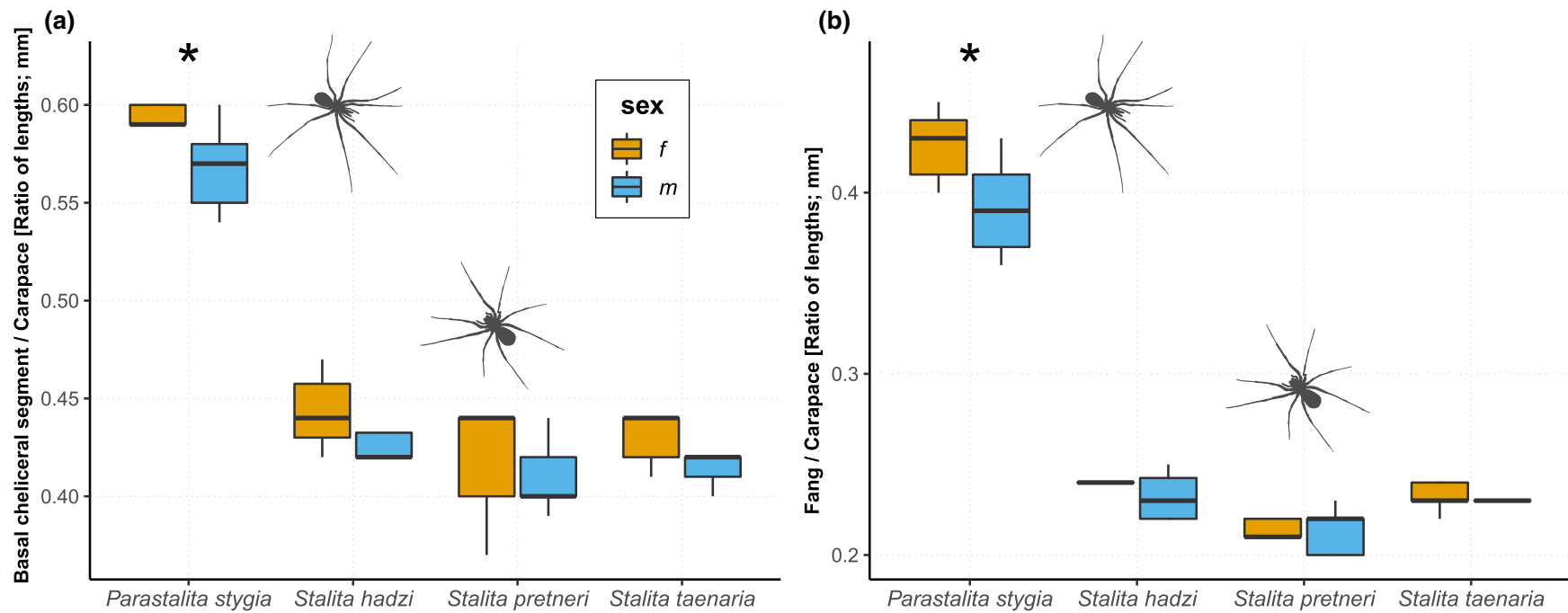

FIGURE 7 Differentiation in the chelicerae and fang shape among the four species. (a) Ratio between the length of the basal cheliceral segment and the carapace. There was a significant difference in the ratio of Parastalita stygia versus all Stalita species based on ANOVA $\left(F_{3,35}=107.6, p<0.001\right.$; asterisk $)$, as well as between males and females of each species $\left(F_{1,35}=5.8, p=0.030\right)$. A post hoc Tukey test showed that all Stalita species were not significantly different from each other at $p<0.05$. (b) Ratio between the length of the fang and the carapace. There was a significant difference in the ratio of $P$. stygia versus all Stalita species based on ANOVA $\left(F_{3,35}=317.3, p<0.001\right.$; asterisk), whereas the differences between sexes only approached statistical significance $\left(F_{1,35}=3.8, p=0.058\right)$. A post hoc Tukey test showed that all Stalita species were not significantly different from each other at $p<0.05$

(Trontelj et al., 2012), but also in other subterranean spiders, such as Troglohyphantes species in the Western Alps (Mammola, et al., 2020).

Stalita pretneri has the largest distribution among the three Stalita species, stretching over $160 \mathrm{~km}$ (Figure 2) and overlapping to a great extent with the distribution of $P$. stygia. In the majority of caves where $S$. pretneri lives in, the two species co-occur. This should translate to a direct competition, since the two species are of comparable size and occupy similar microhabitats. A possible mechanism explaining their coexistence could be a shift in the trophic niche of $P$. stygia towards a more specialized diet. In several Dysdera species, elongation of chelicerae (Arnedo et al., 2007; Rezač et al., 2008) and shift in nutritional physiology (Toft \& Macías-Hernández, 2017; Vizueta et al., 2019) have been shown to be critical adaptations for feeding on woodlice (Crustacea: Isopoda). Woodlice have evolved an array of morphological, chemical and behavioural defensive mechanisms that make them repulsive and unapproachable for many predatory arthropods (Gorvett, 1956). They are a dominant component of the ground-dwelling fauna in caves (Deharveng \& Bedos, 2019), and Dinaric caves are home to a great diversity of species, e.g. in the genus Alpioniscus (Bedek et al., 2019).

Our morphological analysis supports trophic segregation between Parastalita and Stalita (Figure 7). The differences between unmodified and elongated cheliceral morphology appears even more conspicuous in our case than those reported by Rezač et al. (2008) for Dysdera. These authors measured a fang to carapace length ratio (F/C) of 0.41 for unmodified chelicerae, 0.45 for slightly elongated and 0.55 for very elongated; in Stalita species we found average F/C values between 0.21 and 0.24 , while it was two times higher in P. stygia (0.41). The difference in the ratio of basal cheliceral segment to carapace length
(BS/C) was also clear-cut, $0.42-0.44$ for Stalita species versus 0.58 for P. stygia (for Dysdera that value is 0.34 for unmodified, 0.47 for slightly elongated and 0.72 for very elongated). So, due to its elongated chelicerae, $P$. stygia should be able to use woodlice as a food source much more effectively than Stalita (Figure 1c). A specialization for feeding upon an abundant prey item in Dinaric caves, which other predators cannot exploit, would give P. stygia an evolutionary advantage. This adaptation, coupled with the high dispersal potential through the network of fissures in this well-connected karst landscape (Barr, 1967; Culver et al., 2004), would explain the unusually broad distribution of $P$. stygia (240 km long, Figure 2) and the fact that, unlike Stalita, Parastalita individuals are often locally abundant (M. Pavlek, pers. obs.). At the same time, the difference in cheliceral morphology allows $P$. stygia to coexist with other Stalita species.

Niche shift seems to allow S. taenaria to exploit different, warmer and more humid habitats, and indeed this is the only species whose distribution stretches from the coastal areas to mountain regions (from 40 to $1,100 \mathrm{~m}$ a.s.l.). Stalita hadzii has the narrowest distribution centred in the north-east part of the Dinarides. According to $\beta_{\text {richness }}$ values, the reason for this small distribution could be niche contraction, possibly driven by the absence of karst to the north and competitive exclusion by S. taenaria and S. pretneri, distributed eastward and southward respectively.

\subsection{Ecological drivers of species distributions}

Climatic factors, especially precipitation, are the most important predictors that explain the distributions of the studied 
species. Precipitation shapes general underground climatic conditions (Badino, 2010) by ensuring constantly high levels of relative humidity (Bregović \& Zagmajster, 2016). Furthermore, high precipitation regimes are associated with the input of energy (Culver et al., 2006; Mammola \& Leroy, 2018), typically in the form of organic matter transferred underground by percolating waters. It is easy to infer that a higher energy input should translate into a higher abundance and diversity of animals, which in turn determines favourable conditions for apical predators such as Stalita and Parastalita.

Contrary to what was found in other studies (Christman \& Culver, 2001; Pipan \& Culver, 2017), karstic features are not a limiting factor of the species distribution. In this area, karst substrates are widespread and highly porous, ensuring excellent connectivity among subterranean habitats (Barr, 1967; Culver et al., 2004). Interestingly, similar broad north Dinaric distribution patterns have been documented for other specialized subterranean terrestrial invertebrates, such as the beetle Leptodirus hochenwartii Schmidt (1832) (Coleoptera: Leiodidae; Jalžić \& Pretner, 1977; Pretner, 1973), and the millipede Haasia stenopodium Strasser (1966) (Diplopoda: Anthogonidae; Antić et al., 2015).

The presence of fragmented rocks was a further important driver of the species' distributions, particularly, S. pretneri and S. hadzii. On average, all species are found in areas where the volume of coarse rock fragments in soils is $>7 \%$ (Figure $6 \mathrm{~b}$ ), and the depth of the bedrock is $>10 \mathrm{~m}$ (Figure 6a). We introduced these variables in the models to try capturing the availability of MSS-like habitats. The so-called MSS (Mammola, et al., 2016) is a superficial subterranean habitat that originates from the accumulation of rock fragments produced by mechanical weathering of different rocky substrates. The presence of interspersed voids between rocky fragments and a soil layer insulating the system from external weather may lead to the development of a suitable habitat for the subterranean fauna. Although published data about MSS-dwelling species in the Balkan region are scarce, indirect evidence suggests that this could be an important habitat for our model species. In fact, being active hunters rather than web-builders, Dysderidae are frequently associated with MSS habitats (Mammola, et al., 2018), and different species have been collected in MSS in other areas [e.g. Dysdera (Arnedo et al., 2007; Pipan et al., 2010), Harpactocrates and Harpactea (Ledesma et al., 2019)]. This was, however, the first attempt to capture MSS conditions with species distribution models. The development of more specific rasters representing MSS is certainly needed to improve model performance in this sense (Mammola \& Leroy, 2018).

When comparing known occurrence records with the predicted distributions for each species (Figure 4), we observed important distribution gaps. This could be due to the model overestimating species distributions or due to under-sampling, a well-known problem in subterranean biology. Research efforts in exploring subterranean habitats are often concentrated in certain areas, typically in more accessible caves (Zagmajster et al., 2010), whereas the vaster proportion of the subterranean domain remains unexplored (Ficetola et al., 2019; Mammola, et al., 2019). This issue is of particular relevance when it comes to modelling the distribution of subterranean species (Mammola \& Leroy, 2018), but also to estimate species richness patterns (Zagmajster et al., 2008, 2010). For example, in the case of $S$. pretneri, one explanation for large gaps throughout its distribution could be under sampling due to its elusive nature (the species is rarely found and always in low numbers), as well as the lack of investigations in the MSS.

\section{5 | CONCLUSION}

This is the first study on the ecological niche of specialized subterranean Dysderidae, and of any obligatory cave-dwelling species or species group in the Dinaric karst. We demonstrated that cavedwelling spiders can be effectively used as models to revisit classical niche theory. By showing that species' distributions are shaped by both abiotic conditions and competition, we emphasized how even simplified environments still maintain the potential for diversification via niche differentiation. We demonstrated that: (a) phylogenetic relatedness does not reflect niche similarity; (b) closely related species have adapted to different climatic conditions, thereby attaining disjunct distributions, and (c) the prerequisite for sympatry between Parastalita and Stalita is morphological (dietary) segregation. With the accumulation of further knowledge, it will be possible to revisit these processes to account for the interactions with other members of the subterranean community, thereby providing nichebased explanations for the origin and evolution of subterranean biological diversity of the Dinaric karst.

\section{ACKNOWLEDGEMENTS}

Special thanks to Dr. Miquel A. Arnedo for supervising MP and providing laboratory space for genetic analyses, and to Dr. Marco Isaia for useful discussions on species' ecological niches. Alba Enguídanos and Amira Ben Hadid helped in amplifying sequences. Sincere thanks to all members of the Croatian Biospeleological Society, to Fulvio Gasparo, Slavko Polak, Roman Ozimec, and all other speleologists and colleagues who collected the spider material and helped with survey of literature records. Thanks to Universities of Barcelona and Ljubljana for giving access to their collections. Thanks to Tin Rožman for help with sorting out the database, and adjusting maps and photographs, and to Irene Frigo for preparing the spider silhouettes. We are grateful to Lida Lamza and Rebecca Wilson for proof-reading our English, and to Rosemary G. Gillespie, Nuria Macías-Hernández and an anonymous referee for providing insightful suggestions that significantly improved the quality of this work.

\section{DATA AVAILABILITY STATEMENT}

DNA sequences are deposited in GenBank ${ }^{\circledR}$ (see accession codes in Appendix S1). Occurrence points used in this study are available in figshare (https://doi.org/10.6084/m9.figshare.12613193). Coordinates for part of the caves were taken from 'GeoRef' portal (http://www.georef.hr/) and 'Bioportal - Katastar speleoloških objekata RH' (http://www.bioportal.hr/gis/), hosted by Institute for Environment and Nature of Croatia. All environmental variables 
used in the models are available from public repositories (Diktas project website, http://diktas.iwlearn.org/; SoilGrids database, Hengl et al., 2017; and WorldClim website, Fick \& Hijmans, 2017).

\section{ORCID}

Martina Pavlek (D) https://orcid.org/0000-0001-6710-0581

Stefano Mammola iD https://orcid.org/0000-0002-4471-9055

\section{REFERENCES}

Absolon, K., \& Kratochvíl, J. (1932). Zur Kenntnis der höhlenbewohnenden Araneae des illyrischen Karstgebiete. Mitteilungen Über HöhlenUnd Karstforschung, 1932, 73-81.

Antić, D., Dražina, T., Rađa, T., Tomić, V. T., \& Makarov, S. E. (2015). Review of the family Anthogonidae (Diplopoda, Chordeumatida), with descriptions of three new species from the Balkan Peninsula. Zootaxa, 3948(2), 151. https://doi.org/10.11646/zootaxa.3948.2.1

Araújo, M. B., Anderson, R. P., Márcia Barbosa, A., Beale, C. M., Dormann, C. F., Early, R., Garcia, R. A., Guisan, A., Maiorano, L., Naimi, B., O'Hara, R. B., Zimmermann, N. E., \& Rahbek, C. (2019). Standards for distribution models in biodiversity assessments. Science Advances, 5(1), eaat4858. https://doi.org/10.1126/sciadv.aat4858

Arnedo, M. A., Oromi, P., Murria, C., Macias-Hernandez, N., \& Ribera, C. (2007). The dark side of an island radiation: Systematics and evolution of troglobitic spiders of the genus Dysdera Latreille (Araneae:Dysderidae) in the Canary Islands. Invertebrate Systematics, 21(6), 623-660. https://doi.org/10.1071/IS07015

Badino, G. (2010). Underground meteorology - "What's the weather underground ?". Acta Carsologica, 39(3), 427-448. https://doi. org/10.3986/ac.v39i3.74

Barr, T. C. (1967). Observations on the ecology of caves. The American Naturalist, 101, 475-491. https://doi.org/10.1086/282512

Barve, N., Barve, V., Jiménez-Valverde, A., Lira-Noriega, A., Maher, S. P., Peterson, A. T., Soberón, J., \& Villalobos, F. (2011). The crucial role of the accessible area in ecological niche modeling and species distribution modeling. Ecological Modelling, 222, 1810-1819. https://doi. org/10.1016/j.ecolmodel.2011.02.011

Bedek, J., Taiti, S., Bilandžija, H., Ristori, E., \& Baratti, M. (2019). Molecular and taxonomic analyses in troglobiotic Alpioniscus (Illyrionethes) species from the Dinaric Karst (Isopoda: Trichoniscidae). Zoological Journal of the Linnean Society, 20, 1-46. https://doi.org/10.1093/zooli nnean/zlz056

Blonder, B. (2018a). Hypervolume concepts in niche- and trait-based ecology. Ecography, 41(9), 1441-1455. https://doi.org/10.1111/ ecog.03187

Blonder, B. (2018b). Hypervolume: High dimensional geometry and set operations using kernel density estimation, support vector machines, and convex hulls. R package version 2.0.11. Retrieved from https:// cran.r-project.org/package=hypervolume

Blonder, B., Lamanna, C., Violle, C., \& Enquist, B. J. (2014). The n-dimensional hypervolume. Global Ecology and Biogeography, 23(5), 595-609. https://doi.org/10.1111/geb.12146

Blonder, B., Morrow, C. B., Maitner, B., Harris, D. J., Lamanna, C., Violle, C., \& Kerkhoff, A. J. (2018). New approaches for delineating n-dimensional hypervolumes. Methods in Ecology and Evolution, 9(2), 305-319. https://doi.org/10.1111/2041-210X.12865

Boyce, M. S., Vernier, P. R., Nielsen, S. E., \& Schmiegelow, F. K. A. (2002). Evaluating resource selection functions. Ecological Modelling, 157, 281-300. https://doi.org/10.1016/S0304-3800(02)00200-4

Braunisch, V., Coppes, J., Arlettaz, R., Suchant, R., Schmid, H., \& Bollmann, K. (2013). Selecting from correlated climate variables: A major source of uncertainty for predicting species distributions under climate change. Ecography, 36(9), 971-983. https://doi. org/10.1111/j.1600-0587.2013.00138.x
Bregović, P., \& Zagmajster, M. (2016). Understanding hotspots within a global hotspot - Identifying the drivers of regional species richness patterns in terrestrial subterranean habitats. Insect Conservation and Diversity, 9(4), 268-281. https://doi.org/10.1111/icad.12164

Broennimann, O., Di Cola, V., \& Guisan, A. (2018). ecospat: Spatial ecology miscellaneous methods. (R package version 3.0).

Cardoso, P. (2017). red - An R package to facilitate species red list assessments according to the IUCN criteria. Biodiversity Data Journal, 5, e20530.

Cardoso, P., Mammola, S., Rigal, F., \& Carvalho, J. C. (2020). BAT: Biodiversity Assessment Tools. Retrieved from https://Cran.r-Proje ct.Org/Package $=$ BAT

Cardoso, P., Rigal, F., \& Carvalho, J. C. (2015). Biodiversity Assessment Tools, an $\mathrm{R}$ package for the measurement and estimation of alpha and beta taxon, phylogenetic and functional diversity. Methods in Ecology and Evolution, 6(2), 232-236. https://doi. org/10.1111/2041-210X.12310

Carvalho, J. C., \& Cardoso, P. (2020). Decomposing the causes for niche differentiation between species using hypervolumes. Frontiers in Ecology and Evolution, 8, 243. https://doi.org/10.3389/ fevo.2020.00243

Chase, J. M., \& Leibold, M. A. (2003). Ecological niches: Linking classical and contemporary approaches (pp. 1-221). University of Chicago Press. Retrieved from https://press.uchicago.edu/ucp/books/book/ chicago/E/bo3638660.html

Christman, M. C., \& Culver, D. C. (2001). The relationship between cave biodiversity and available habitat. Journal of Biogeography, 28(3), 367-380. https://doi.org/10.1046/j.1365-2699.2001.00549.x

Culver, D. C., Christman, M. C., Šereg, I., Trontelj, P., \& Sket, B. (2004). The location of terrestrial species-rich caves in a cave-rich area. Subterranean Biology, 2, 27-32.

Culver, D., Deharveng, L., Bedos, A., J. Lewis, J., Madden, M., R. Reddell, J., Sket, B., Trontelj, P., \& White, D. (2006). The mid-latitude biodiversity ridge in terrestrial cave fauna. Ecography, 29, 120-128. https:// doi.org/10.1111/j.2005.0906-7590.04435.x

Culver, D. C., \& Pipan, T. (2015). Shifting paradigms of the evolution of cave life. Acta Carsologica, 44, 415-425.

Culver, D. C., \& Pipan, T. (2019). The biology of caves and other subterranean habitats (2nd ed.). Oxford University Press.

De Busschere, C., Hendrickx, F., Van Belleghem, S. M., Backeljau, T., Lens, L., \& Baert, L. (2010). Parallel habitat specialization within the wolf spider genus Hogna from the Galápagos. Molecular Ecology, 19(18), 4029-4045. https://doi.org/10.1111/j.1365-294X.2010.04758.x

Deeleman-Reinhold, C. L. (1971). Beitrag zur Kenntnis höhlenbewohnender Dysderidae (Araneida) aus Jugoslawien. Razpr. Slov. Akad. Znan. Umet., 14, 95-120.

Deharveng, L., \& Bedos, A. (2019). Diversity of terrestrial invertebrates in subterranean habitats. In Cave ecology, Ecological Studies (Vol. 235, pp. 107-172). Cham, Switzerland: Springer.

Duong, T., \& Hazelton, M. L. (2005). Cross-validation bandwidth matrices for multivariate kernel density estimation. Scandinavian Journal of Statistics, 32, 485-506. https://doi.org/10.1111/j.1467-9469.2005.00445.x

Ficetola, G. F., Canedoli, C., \& Stoch, F. (2019). The Racovitzan impediment and the hidden biodiversity of unexplored environments. Conservation Biology, 33(1), 214-216. https://doi.org/10.1111/cobi.13179

Fick, S. E., \& Hijmans, R. J. (2017). Worldclim 2: New 1-km spatial resolution climate surfaces for global land areas. International Journal of Climatology, 37(12), 4302-4315. https://doi.org/10.1002/joc.5086

Fišer, C., Blejec, A., \& Trontelj, P. (2012). Niche-based mechanisms operating within extreme habitats: A case study of subterranean amphipod communities. Biology Letters, 8(4), 578-581. https://doi. org/10.1098/rsbl.2012.0125

Gavrilets, S., \& Losos, J. B. (2009). Adaptive radiation: Contrasting theory with data. Science, 323, 732-737. https://doi.org/10.1126/scien ce.1157966 
Gers, C. (1998). Diversity of energy fluxes and interactions between arthropod communities: From soil to cave. Acta Oecologica, 19(3), 205-213. https://doi.org/10.1016/S1146-609X(98)80025-8

Gibert, J., \& Deharveng, L. (2002). Subterranean ecosystems: A truncated functional biodiversity. BioScience, 52(6), 473. https://doi. org/10.1641/0006-3568(2002)052[0473:seatfb]2.0.co;2

Gillespie, R. G., Bennett, G. M., De Meester, L., Feder, J. L., Fleischer, R. C., Harmon, L. J., Hendry, A. P., Knope, M. L., Mallet, J., Martin, C., Parent, C. E., Patton, A. H., Pfennig, K. S., Rubinoff, D., Schluter, D., Seehausen, O., Shaw, K. L., Stacy, E., Stervander, M., \& Wogan, G. O. U. (2020). Comparing adaptive radiations across space, time, and taxa. Journal of Heredity, 111(1), 1-20. https://doi.org/10.1093/jhere d/esz064

Gorvett, H. (1956). Tegumental glands and terrestrial life in woodlice. Proceedings of the Zoological Society of London, 126, 291-314. https:// doi.org/10.1111/j.1096-3642.1956.tb00439.x

Grant, P. R., \& Grant, B. R. (2008). How and why species multiply. The radiation of Darwin's finches. Princeton Series in Evolutionary Biology. Princeton University Press. Retrieved from https://press.princeton.edu/books/ paperback/9780691149998/how-and-why-species-multiply

Hanson, J. O., Rhodes, J. R., Butchart, S. H., Buchanan, G. M., Rondinini, C., Ficetola, G. F., \& Fuller, R. A. (2020). Global conservation of species' niches. Nature, 580(7802), 232-234.

Hengl, T., Mendes de Jesus, J., Heuvelink, G. B. M., Ruiperez Gonzalez, M., Kilibarda, M., Blagotić, A., Shangguan, W., Wright, M. N., Geng, X., Bauer-Marschallinger, B., Guevara, M. A., Vargas, R., MacMillan, R. A., Batjes, N. H., Leenaars, J. G. B., Ribeiro, E., Wheeler, I., Mantel, S., \& Kempen, B. (2017). SoilGrids250m: Global gridded soil information based on machine learning. PLoS One, 12, e0169748. https://doi. org/10.1371/journal.pone.0169748

Hijmans, R. J., Phillips, S., Leathwick, J., \& Elith, J. (2014). dismo: Species distribution modeling. R package version 1.0-5.

Hirzel, A. H., Le Lay, G., Helfer, V., Randin, C., \& Guisan, A. (2006). Evaluating the ability of habitat suitability models to predict species presences. Ecological Modelling, 199, 142-152. https://doi.org/10.1016/j.ecolm odel.2006.05.017

Holt, R. D. (2009). Bringing the Hutchinsonian niche into the 21st century: Ecological and evolutionary perspectives. Proceedings of the National Academy of Sciences of the United States of America, 106(2), 19659-19665. https://doi.org/10.1073/pnas.0905137106

Hutchinson, G. E. (1957). Concluding remarks. Cold Spring Harbor Symposia on Quantitative Biology, 22, 415-427. https://doi.org/10.1101/ SQB.1957.022.01.039

Jalžić, B., \& Pretner, E. (1977). Prilog poznavanju faune koleoptera pećina i jama Hrvatske. Krš Jugoslavije, 9(5), 239-271.

Joseph, G. (1882). Systematisches Verzeichniss der in Tropfsteingrotten von Krain einheimischen Arthropoden, nebst Diagnosen der vom Verfasser entdecken und bischer noch nicht beschreibenen Arten. Berliner Entomologische Zeitschrift, 1882, 1-50.

Kalyaanamoorthy, S., Minh, B. Q., Wong, T. K. F., Von Haeseler, A., \& Jermiin, L. S. (2017). ModelFinder: Fast model selection for accurate phylogenetic estimates. Nature Methods, 14(6), 587-589. https://doi. org/10.1038/nmeth.4285

Katoh, K., Misawa, K., Kuma, K., \& Miyata, T. (2002). MAFFT: A novel method for rapid multiple sequence alignment based on fast Fourier transform. Nucleic Acids Research, 30(14), 3059-3066. https://doi. org/10.1093/nar/gkf436

Kearse, M., Moir, R., Wilson, A., Stones-Havas, S., Cheung, M., Sturrock, S., Buxton, S., Cooper, A., Markowitz, S., Duran, C., Thierer, T., Ashton, B., Meintjes, P., \& Drummond, A. (2012). Geneious Basic: An integrated and extendable desktop software platform for the organization and analysis of sequence data. Bioinformatics, 28(12), 1647-1649. https://doi.org/10.1093/bioinformatics/bts199

Kennedy, S., Lim, J. Y., Clavel, J., Krehenwinkel, H., \& Gillespie, R. G. (2019). Spider webs, stable isotopes and molecular gut content analysis: Multiple lines of evidence support trophic niche differentiation in a community of Hawaiian spiders. Functional Ecology, 33(9), 1722-1733. https://doi.org/10.1111/1365-2435.13361

Koch, C. L. (1837). Übersicht des Arachnidensystems (Vol. 1, pp. 1-39). Nürnberg, C.H. Zeh. https://doi.org/10.5962/bhl.title.39561

Kratochvíl, J. (1934). Pregled pecinskih paukova u Jugoslaviji [Liste générale des Araignées cavernicoles en Yougoslavie]. Prirodoslovne Razprave, 2, 165-226.

Kratochvíl, J. (1970). Cavernicole Dysderae. Acta Sc Nat Brno, 4, 1-62.

Lanfear, R., Frandsen, P. B., Wright, A. M., Senfeld, T., \& Calcott, B. (2017). Partitionfinder 2: New methods for selecting partitioned models of evolution for molecular and morphological phylogenetic analyses. Molecular Biology and Evolution, 34(3), 772-773. https://doi. org $/ 10.1093 / \mathrm{molbev} / \mathrm{msw} 260$

Ledesma, E., Jiménez-Valverde, A., de Castro, A., Aguado-Aranda, P., \& Ortuño, V. M. (2019). The study of hidden habitats sheds light on poorly known taxa: Spiders of the Mesovoid Shallow substratum. ZooKeys, 2019(841), 39-59. https://doi.org/10.3897/zooke ys.841.33271

Liu, H., Ye, Q., \& Wiens, J. J. (2020). Climatic-niche evolution follows similar rules in plants and animals. Nature Ecology \& Evolution, 4(5), 753-763. https://doi.org/10.1038/s41559-020-1158-x

Mammola, S. (2019a). Finding answers in the dark: Caves as models in ecology fifty years after Poulson and White. Ecography, 42(7), 13311351. https://doi.org/10.1111/ecog.03905

Mammola, S. (2019b). Assessing similarity of $n$-dimensional hypervolumes: Which metric to use? Journal of Biogeography, 46(9), 20122023. https://doi.org/10.1111/jbi.13618

Mammola, S., Amorim, I. R., Bichuette, M. E., Borges, P. A. V., Cheeptham, N., Cooper, S. J. B., Culver, D. C., Deharveng, L., Eme, D., Ferreira, R. L., Fišer, C., Fišer, Ž., Fong, D. W., Griebler, C., Jeffery, W. R., Jugovic, J., Kowalko, J. E., Lilley, T. M., Malard, F., \& Cardoso, P. (2020). Fundamental research questions in subterranean biology. Biological Reviews (in press). https://doi.org/10.1111/BRV.12642

Mammola, S., Arnedo, M. A., Fišer, C., Cardoso, P., Dejanaz, A. J., \& Isaia, M. (2020). Environmental filtering and convergent evolution determine the ecological specialization of subterranean spiders. Functional Ecology, 34(5), 1064-1077. https://doi.org/10.1111/1365-2435.13527

Mammola, S., Arnedo, M. A., Pantini, P., Piano, E., Chiappetta, N., \& Isaia, M. (2018). Ecological speciation in darkness? Spatial niche partitioning in sibling subterranean spiders (Araneae: Linyphiidae: Troglohyphantes). Invertebrate Systematics, 32(5), 1069-1082. https:// doi.org/10.1071/IS17090

Mammola, S., \& Cardoso, P. (2020). Functional diversity metrics using kernel density n-dimensional hypervolumes. Methods in Ecology and Evolution, 11(8), 986-995. https://doi.org/10.1111/2041-210X.13424

Mammola, S., Cardoso, P., Culver, D. C., Deharveng, L., Ferreira, R. L. Fišer, C., Galassi, D. M. P., Griebler, C., Halse, S., Humphreys, W. F., Isaia, M., Malard, F., Martinez, A., Moldovan, O. T., Niemiller, M. L., Pavlek, M., Reboleira, A. S. P. S., Souza-Silva, M., Teeling, E. C., \& Zagmajster, M. (2019). Scientists' warning on the conservation of subterranean ecosystems. BioScience, 69(8), 641-650. https://doi. org/10.1093/biosci/biz064

Mammola, S., Cardoso, P., Ribera, C., Pavlek, M., \& Isaia, M. (2018). A synthesis on cave-dwelling spiders in Europe. Journal of Zoological Systematics and Evolutionary Research, 56(3), 301-316. https://doi. org/10.1111/jzs.12201

Mammola, S., Giachino, P. M., Piano, E., Jones, A., Barberis, M., Badino, G., \& Isaia, M. (2016). Ecology and sampling techniques of an understudied subterranean habitat: The Milieu Souterrain Superficiel (MSS). The Science of Nature, 103(11-12), 88. https://doi.org/10.1007/s0011 4-016-1413-9

Mammola, S., \& Isaia, M. (2017a). Spiders in caves. Proceedings of the Royal Society B: Biological Sciences, 284(1853), 20170193. https://doi. org/10.1098/rspb.2017.0193 
Mammola, S., \& Isaia, M. (2017b). Rapid poleward distributional shifts in the European cave-dwelling Meta spiders under the influence of competition dynamics. Journal of Biogeography, 44(12), 2789-2797.

Mammola, S., \& Leroy, B. (2018). Applying species distribution models to caves and other subterranean habitats. Ecography, 41(7), 1194-1208. https://doi.org/10.1111/ecog.03464

Mammola, S., Piano, E., \& Isaia, M. (2016). Step back! Niche dynamics in cave-dwelling predators. Acta Oecologica, 75, 35-42. https://doi. org/10.1016/j.actao.2016.06.011

Mammola, S., Schönhofer, A. L., \& Isaia, M. (2019). Tracking the ice: Subterranean harvestmen distribution matches ancient glacier margins. Journal of Zoological Systematics and Evolutionary Research, 57(3), 548-554. https://doi.org/10.1111/jzs.12264

McGee, M. D., Borstein, S. R., Meier, J. I., Marques, D. A., Mwaiko, S., Taabu, A., Kishe, M. A., O'Meara, B., Bruggmann, R., Excoffier, L., Seehausen, O. (2020). The ecological and genomic basis of explosive adaptive radiation. Nature. http://dx.doi.org/10.1038/s4158 6-020-2652-7

Minh, B. Q., Schmidt, H. A., Chernomor, O., Schrempf, D., Woodhams, M. D., von Haeseler, A., Lanfear, R. (2020). IQ-TREE 2: New Models and Efficient Methods for Phylogenetic Inference in the Genomic Era. Molecular Biology and Evolution, 37(5), 1530-1534. http://dx.doi. org/10.1093/molbev/msaa015

Morales, N. S., Fernández, I. C., \& Baca-González, V. (2017). MaxEnt's parameter configuration and small samples: Are we paying attention to recommendations? A systematic review. PeerJ, 5, e3093. https:// doi.org/10.7717/peerj.3093

Muscarella, R., Galante, P. J., Soley-Guardia, M., Boria, R. A., Kass, J. M., Uriarte, M., \& Anderson, R. P. (2014). ENMeval: An R package for conducting spatially independent evaluations and estimating optimal model complexity for ecological niche models. Methods in Ecology and Evolution, 6, 1198-1205.

Novak, T., Tkvac, T., Kuntner, M., Arnett, E. A., Delakorda, S. L., Perc, M., \& Janžekovič, F. (2010). Niche partitioning in orbweaving spider Meta menardi and Metellina merianae (Tetragnathidae). Acta Oecologica, 36, 522-529.

Pavlek, M., \& Ribera, C. (2017). Kryptonesticus deelemanae gen. et sp. nov. (Araneae, Nesticidae), with notes on the Mediterranean cave species. European Journal of Taxonomy, 262, 1-27. https://doi. org/10.5852/ejt.2017.262

Peterson, A. T. (1999). Conservatism of ecological niches in evolutionary time. Science, 285(5431), 1265-1267. https://doi.org/10.1126/scien ce.285.5431.1265

Pipan, T., \& Culver, D. C. (2017). The unity and diversity of the subterranean realm with respect to invertebrate body size. Journal of Cave and Karst Studies, 79(1), 1-9. https://doi.org/10.4311/2016L SC0119

Pipan, T., López, H., Oromí, P., Polak, S., \& Culver, D. C. (2010). Temperature variation and the presence of troglobionts in terrestrial shallow subterranean habitats. Journal of Natural History, 45(3-4), 253-273. https://doi.org/10.1080/00222933.2010.523797

Platania, L., Pavlek, M., \& Arnedo, M. A. (2020). Testing the monophyly of the ground-dweller spider genus Harpactea Bristowe, 1939 (Araneae. Dysderidae) with the description of three new species. Systematics and Biodiversity, 18(7), 688-707. https://doi.org/10.1080/14772 000.2020 .1776786

Poulson, T. L., \& White, W. B. (1969). The cave environment. Science, 165, 971-981. https://doi.org/10.1126/science.165.3897.971

Pretner, E. (1973). Koleopterološka fauna pećina i jama Hrvatske s historijskim pregledom istraživanja. Krš Jugoslavije, 8(6), 101-239.

R Core Team. (2018). R: A language and environment for statistical computing. R Foundation for Statistical Computing. Retrieved from www.R-project.org/

Rambaut, A., Drummond, A. J., Xie, D., Baele, G., \& Suchard, M. A. (2018). Posterior summarization in Bayesian phylogenetics using Tracer 1.7.
Systematic Biology, 67(5), 901-904. https://doi.org/10.1093/sysbio/ syy032

Resende, L. P. A., \& Bichuette, M. E. (2016). Sharing the space: Coexistence among terrestrial predators in Neotropical caves. Journal of Natural History, 50, 2107-2128. https://doi.org/10.1080/00222 933.2016.1193641

Rezač, M., Pekar, S., \& Lubin, Y. (2008). How oniscophagous spiders overcome woodlouse armour. Journal of Zoology, 275, 64-71. https://doi. org/10.1111/j.1469-7998.2007.00408.x

Roewer, C. F. (1931). Arachnoideen aus südostalpinen Höhlen gesammelt von Herrn Karl Strasser in den Jahren 1929 und 1930. Mitteilungen Über Höhlen- Und Karstforschung, 1931, 1-17.

Ronquist, F., \& Huelsenbeck, J. P. (2003). MrBayes 3: Bayesian phylogenetic inference under mixed models. Bioinformatics, 19(12), 15721574. https://doi.org/10.1093/bioinformatics/btg180

Sánchez-Fernández, D., Rizzo, V., Bourdeau, C., Cieslak, A., Comas, J., Faille, A., Fresneda, J., Lleopart, E., Millán, A., Montes, A., Pallares, S., $\&$ Ribera, I. (2018). The deep subterranean environment as a potential model system in ecological, biogeographical and evolutionary research. Subterranean Biology, 25, 1-7. https://doi.org/10.3897/subtb iol.25.23530

Schiödte, J. C. (1847). Forelöbig Beretning om Untersögelser om den underjordiske Fauna i Hulerme i Krain og Istrien. Oversigt over Det Kongelige Danske Videnskabernes Selskabs Forhandlinger, 1847, 75-81.

Schmidt, F. (1832). Beitrag zu Krain's Fauna. Leptodirus Hochenwartii, n. g., n. sp. Illyrisches Blatt., 3, 9-10.

Sket, B. (2012). Diversity patterns in the Dinaric Karst. In W. B. White, \& D. C. Culver (Eds.), Encyclopedia of caves (2nd ed., pp. 228-238). Elsevier Academic Press.

Sket, B., Paragamian, K. K., \& Trontelj, P. (2004). A census of the obligate subterranean fauna of the Balkan Peninsula. Balkan Biodiversity: Pattern and Process in the European Hotspot, 1540, 309-322. https:// doi.org/10.1007/978-1-4020-2854-0_18

Strasser, K. (1966). Neue Diplopoden aus Höhlen Jugoslawiens. Senck. Biol., 47(1), 379-398.

Toft, S., \& Macías-Hernández, N. (2017). Metabolic adaptations for isopod specialization in three species of Dysdera spiders from the Canary Islands. Physiological Entomology, 42(2), 191-198. https://doi. org/10.1111/phen.12192

Trontelj, P., Blejec, A., \& Fišer, C. (2012). Ecomorphological convergence of cave communities. Evolution, 66(12), 3852-3865. https://doi. org/10.1111/j.1558-5646.2012.01734.x

Vizueta, J., Macías-Hernández, N., Arnedo, M. A., Rozas, J., \& Sánchez-Gracia, A. (2019). Chance and predictability in evolution: The genomic basis of convergent dietary specializations in an adaptive radiation. Molecular Ecology, 28(17), 4028-4045. https://doi.org/10.1111/mec.15199

Wang, C., \& Li, S. (2010). Two new species of the spider genus Cataleptoneta from Balkan Peninsula (Araneae, Leptonetidae). Zootaxa, 2730, 57-68. https://doi.org/10.11646/zootaxa.2730.1.4

Wiens, J. J., \& Graham, C. H. (2005). Niche conservatism: Integrating evolution, ecology, and conservation biology. Annual Review of Ecology, Evolution, and Systematics, 36(1), 519-539. https://doi.org/10.1146/ annurev.ecolsys.36.102803.095431

Zagmajster, M., Culver, D. C., Christman, M. C., \& Sket, B. (2010). Evaluating the sampling bias in pattern of subterranean species richness: Combining approaches. Biodiversity and Conservation, 19(11), 3035-3048. https://doi.org/10.1007/s10531-010-9873-2

Zagmajster, M., Culver, D. C., \& Sket, B. (2008). Species richness patterns of obligate subterranean beetles (Insecta: Coleoptera) in a global biodiversity hotspot - Effect of scale and sampling intensity. Diversity and Distributions, 14(1), 95-105. https://doi. org/10.1111/j.1472-4642.2007.00423.x

Zupan Hajna, N. (2019). Dinaric karst-Geography and geology. In Encyclopedia of caves (3rd edition, pp. 353-362). London, UK: Elsevier Inc. 
Zuur, A. F., leno, E. N., \& Elphick, S. C. (2010). A protocol for data exploration to avoid common statistical problems. Methods in Ecology and Evolution, 1, 3-14. https://doi.org/10.1111/j.2041-210X.2009.00001.x

\section{BIOSKETCH}

Martina Pavlek is a biologist who studies taxonomy, systematics, phylogeny, biogeography and ecology of cave-dwelling spiders and other groups in the Dinarides, and the effects of climatic changes on these endemic taxa with low tolerance to environmental disturbances.

Stefano Mammola is an ecologist interested in different modelling methods. He uses simplified ecological settings, especially caves, as scalable model systems in which to minimize confounding effects and reduce the number of parameters needed to explore different eco-evolutionary processes.

Authors contribution: MP and SM conceived the study and wrote the text. MP collected data, measured morphological characters and performed molecular laboratory work and analyses. SM analysed ecological data.

\section{SUPPORTING INFORMATION}

Additional supporting information may be found online in the Supporting Information section.

How to cite this article: Pavlek M, Mammola S. Niche-based processes explaining the distributions of closely related subterranean spiders. J. Biogeogr.2020;00:1-16. https://doi. org/10.1111/jbi.13987 